\title{
Treatment of postherpetic neuralgia
}

Steven Lovitt, MD

\section{What Is Postherpetic Neuralgia $(\mathrm{PHN})$ ?}

The syndrome of PHN consists of persistent pain after a nerve has been infected with the varicella zoster virus (VZV). This infection is commonly called shingles. More information about shingles can be found on the next page. The first sign of shingles is usually a gradual onset of burning, tingling, or numbness in the area supplied by the infected nerve. Over half the time, the infected nerve is on the trunk, resulting in symptoms in a strip across half of the back or abdomen like a belt. Approximately $15 \%$ of cases involve the nerves of the face. This is soon followed by pain of variable intensity. PHN occurs in approximately 10 to 15 percent of all patients with shingles, most commonly in people over 60 years of age. The symptoms gradually disappear in most people; however, in some patients, PHN persists for years. PHN is more common after shingles affecting the face than the trunk. The more severe the initial shingles involvement, the greater the likelihood of the pain becoming chronic. Pain is usually described as a constant nagging, burning, aching, tearing, and itching, upon which may be superimposed shocks and jabs. Many patients describe "tenderness" even with light contact with clothing. Although many drugs have been used to treat PHN, gabapentin and topical lidocaine are the only drugs that have been federally approved in treating PHN.

\section{New Treatments For PHN}

In this issue of Neurology, two research groups report the results of studies investigating two new treatments for PHN. Quan et al. (Quan
D, Wellish M, Gilden DH. Topical ketamine treatment of postherpetic neuralgia.) describe their experience with ketamine gel, and Dworkin et al. (Dworkin RH, Corbin AE, Young JP Jr. Pregabalin for the treatment of postherpetic neuralgia: A randomized, placebo-controlled trial.) describe their experience with pregabalin. Pregabalin has been shown to be safe and effective in patients with painful neuropathy due to diabetes mellitus.

\section{How The Study Was Performed}

\section{Treatment Of PHN With Ketamine Gel}

The authors treated 23 patients with PHN two-three times daily over the skin where pain was severe. Sixteen of these patients had no other changes made to their medications when ketamine was added; seven had other medications added or had a change in the dose of other medicines when ketamine was added. After treatment with topical ketamine was started, patients were asked to rate their pain as severe, moderate, or mild. Patients rated their pain either in a follow-up office visit, by letter, or by telephone report.

\section{Treatment Of PHN With Pregablin}

The authors treated 173 patients with PHN; 89 patients received pregabalin, while 84 received placebo (sugar pill). Patients taking antiepileptic medicines, oral corticosteroids, topical agents, benzodiazepines, and muscle relaxants were not eligible. Patients rated their pain on a scale of 1-10 (0 = no pain; $10=$ worst possible pain) four times per day; all patients had an average score $\geq 4$ for the week before receiving pregabalin (or pla- cebo). Patients rated their pain every morning based on the last 24 hours for 8 weeks; the main result that was studied was the average of the last seven daily ratings. The authors also studied the degree that pain interfered with sleep; subjective quality of life measurements; and overall patient and doctor impression of change during the study.

\section{What Did The Results Show?}

\section{Treatment Of PHN With Ketamine Gel}

Of the 16 patients who had no other changes made to their medicines when ketamine was started, five reported that their pain diminished from severe to moderate, while another five reported that it diminished from severe to mild. Of the seven patients who started ketamine and new medicines simultaneously, two reported improvement in pain from severe to moderate; another three reported improvement from severe to mild. Overall, 15 of $23(65 \%)$ of patients reported significant improvement in pain, while eight did not.

\section{Treatment Of PHN With Pregablin}

Patients treated with pregabalin had a statistically significant painrating decrease when compared with patients taking placebo (3.60 vs 5.29). The number of patients with at least a $30 \%$ or $50 \%$ reduction in pain was greater in the pregabalin than the placebo group. Sleep improved in patients taking pregabalin when compared with placebo. The patients and doctors were more likely to report overall improvement on pregabalin than on placebo. 


\section{How Serious Were The Side Effects?}

\section{Treatment Of PHN With Ketamine Gel}

Two patients reported skin irritation at the site of gel application that resolved after they stopped using ketamine. No other side effects were reported.

\section{Treatment Of PHN With Pregablin}

Eighty-seven percent of patients treated with pregabalin reported a side effect, compared with $63 \%$ of the patients taking placebo. Most of these patients felt that the side effect was mild or moderate. The most common side effects were dizziness, sleepiness, swelling of the legs, and dry mouth.

\section{Summary}

In most patients, PHN gradually resolves over months. However, before the pain resolves, it may be difficult to control. In those patients in whom PHN persists for longer periods of time, adequate pain control may be even more difficult. Taken together, these studies provide two additional PHN-treatment options. While they may not be the first agents utilized in treatment, patients who do not have adequate pain control or who are unable to start other medicines may benefit from pregabalin or topical lidocaine.

\section{What Is Shingles?}

Shingles is caused by an infection of a nerve with VZV. VZV is a highly contagious virus that is best known for causing varicella (chickenpox). The initial symptoms are rash, fever, and malaise. Within a few days, a rash appears; the skin lesions usually start on the trunk, then spread to the arms and legs. The lesions crust over 1-2 weeks, and the rash usually resolves over $3-5$ weeks. Although varicella is usually considered to be a minor infection, it can cause serious complications such as encephalitis and pneumonia, especially among the elderly and those with suppression of the immune system. According to the Centers for Disease Control and Prevention, each year, in the US alone, varicella complications results in the hospitalization of approximately 11,000 individuals (the majority of whom were previously healthy) and 105 deaths. Cases most commonly occur in the late winter and spring. Varicella is highly contagious; it is spread primarily by secretions of the respiratory tract such as coughing and sneezing. It is contagious from a few days before the rash appears until all lesions have dried up and become scabs. After exposure to the disease, it can take up to 3 weeks before the rash appears.

\section{Can Varicella Be Prevented?}

A vaccine was introduced in 1995 that has lowered the incidence of varicella by about $80 \%$. Before the vaccine was available, about 4 million people contracted varicella each year, most of them before reaching age 18 years. The American Academy of Pediatrics recommends that adults who have not had varicella and all children receive the vaccine.

\section{How Does Shingles Occur?}

After an episode of varicella, the virus becomes dormant inside nerve cells. Years later, the virus can awaken, resulting in a painful rash along the skin supplied by the nerve cells. Exactly why and how the virus awakens is unclear. It more commonly occurs in people over age 50 years and in those who have a weakened immune system brought on by an illness such as cancer or AIDS and certain medical treatments such as chemotherapy.

\section{What Are The Signs And Symptoms Of Shingles?}

The earliest signs of shingles include burning or shooting pain, numbness, or tingling in an isolated region on one side of the body or face. As these symptoms are somewhat vague, they are not recognized until the rash appears on the skin up to 2 weeks later, usually in a band on one side of the body, or clustered on one side of the face (where there previously was pain). Within days, the rash become fluid-filled blisters. Over a few weeks, they slowly crust, scab, and heal. Once the blisters heal, pain may continue for 1 month or longer. The skin may also loose feeling and become discolored where the rash was.

\section{How Often Does PHN Occur, And Who Is More Likely To Get It?}

$\mathrm{PHN}$ is more common after shingles affecting the face than it is after shingles involving the trunk. It is more likely to occur after more severe zoster involvement. PHN occurs in about $10-15 \%$ of all herpes zoster patients, but the incidence progressively increases to more than $60 \%$ in patients over age 60 years. However, the symptoms gradually disappear in most, and are still present at 6 months in only $13 \%$ of those older than 60 . In some patients, however, PHN persists for years or even a lifetime.

\section{What Can Be Done To Treat PHN?}

Treatment with antiviral medications during the first 72 hours after the shingles rash appears reduces the probability of developing PHN. Once PHN has occurred, the focus turns to treating the symptoms. Gabapentin and topical lidocaine are the only drugs that have been federally approved in treating PHN. However, many other drugs have been shown to be effective in treating $\mathrm{PHN}$.

\section{For More Information \\ VZV Research Foundation \\ 40 East 72nd Street \\ New York, NY 10021}

(212) 472-3181

http://www.vzvfoundation.org/ 


\section{Neurology}

\section{Treatment of postherpetic neuralgia}

Steven Lovitt

Neurology 2003;60;E6-E7

DOI 10.1212/WNL.60.8.E6

This information is current as of April 22, 2003

\section{Updated Information \&} Services

Permissions \& Licensing

Reprints including high resolution figures, can be found at: http://n.neurology.org/content/60/8/E6.full

Information about reproducing this article in parts (figures,tables) or in its entirety can be found online at:

http://www.neurology.org/about/about_the_journal\#permissions

Information about ordering reprints can be found online:

http://n.neurology.org/subscribers/advertise

Neurology ${ }^{\circledR}$ is the official journal of the American Academy of Neurology. Published continuously since 1951, it is now a weekly with 48 issues per year. Copyright . All rights reserved. Print ISSN: 0028-3878. Online ISSN: 1526-632X.

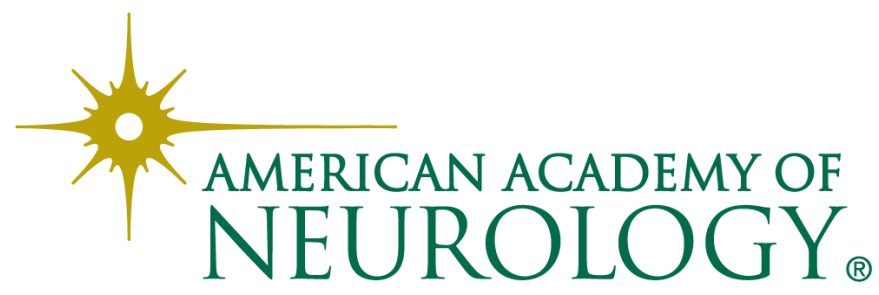

